\title{
Não conformidades logísticas tratadas sob a égide da Teoria Evolucionária
}

\author{
Logistics non-conformances managed under the aegis of Evolutionary Theory \\ No conformidades logísticas tratadas en la agenda de Teoría de la Evolución
}

Recebido: 21/11/2021 | Revisado: 28/11/2021 | Aceito: 04/12/2021 | Publicado: 14/12/2021

\author{
Daiane Przybyczewski \\ ORCID: https://orcid.org/0000-0002-0993-8754 \\ Universidade Estadual do Centro Oeste, Brasil \\ E-mail: daiane_prz@outlook.com \\ Telma Regina Stroparo \\ ORCID: https://orcid.org/0000-0001-8446-992X \\ Universidade Estadual do Centro Oeste, Brasil \\ E-mail: telma@unicentro.br
}

\begin{abstract}
Resumo:
Com o objetivo de verificar de que forma a Teoria Evolucionária pode contribuir para a melhoria dos processos logísticos, a presente pesquisa classifica-se metodologicamente quanto aos objetivos, como descritiva; quanto aos procedimentos como bibliográfica, documental e pesquisa ação. Quanto à abordagem do problema caracteriza-se como qualitativa. Para realização da pesquisa foram coletadas as inconformidades logísticas de uma indústria de bens de consumo analisadas e tratadas sob a égide da Teoria Evolucionária. Os resultados encontrados apontam para relevância das rotinas no aprendizado que, uma vez aprimoradas, refletem-se em soluções para os problemas, em virtude da especialização e aprendizado advindos com a otimização dos processos.
\end{abstract}

Palavras-chave: Teoria evolucionária; Logística; Inovação.

\begin{abstract}
The present investigation aim is to verify how the Evolutionary Theory can contribute to the improvement of the logistics processes. Methodologically, we describe it as descriptive, to comply with the objectives; as bibliographic, documental, and action research, to comply with the procedures. To approach the research problem, we used the qualitative method. To perform the research, we collected the logistics non-conformances of a consumer goods industry analyzed and managed under the aegis of Evolutionary Theory. The results found point to the relevance of the routines in learning. These routines, once improved, are reflected in solutions to the problems, due to the specialization and learning coming from the process optimization.
\end{abstract}

Keywords: Evolutionary theory; Logistics; Innovation.

\section{Resumen}

Con el fin de verificar cómo la Teoría Evolutiva puede contribuir al mejoramiento de los procesos logísticos, esta investigación se clasifica metodológicamente en cuanto a sus objetivos, como descriptiva; sobre procedimientos como la investigación bibliográfica, documental y acción. En cuanto al enfoque del problema, se caracteriza por ser cualitativo. Para la realización de la investigación se recogieron, analizaron y trataron las no conformidades logísticas de una industria de bienes de consumo bajo la égida de la Teoría Evolutiva. Los resultados encontrados apuntan a la relevancia de las rutinas de aprendizaje que, una vez mejoradas, se reflejan en la solución de problemas, debido a la especialización y el aprendizaje derivado de la optimización de procesos.

Palabras clave: Teoría evolutiva; Logística; Innovación.

\section{Introdução}

Tomando por base a premissa de que aprendizagem organizacional é um processo no qual a organização busca obter informações, conhecimentos e/ou capacidades para melhorar sua habilidade de funcionar e competir. (Yuliansyah \& Jermias, 2018; Mohammad, 2019), a presente pesquisa tem como objetivo verificar de que forma a Teoria Evolucionária pode contribuir para a melhoria dos processos logísticos.

Teoria Evolucionária não é nova no contexto econômico, mas suas premissas remetem a conceitos aplicáveis na rotina empresarial, seja no estudo dos fluxos e processos, e/ou tecnologias inovativas. De modo geral, as teorias que tangem ao desenvolvimento capitalista tiveram seu surgimento com a mecanização da produção e relacionamento comercial tal como conhecemos. Buscavam explicar o fluxo, as consequências sociais e o impacto na organização ou no meio como um todo. Tais 
teorias tem relação com tecnologia, inovação e desenvolvimento, conceitos frequentemente utilizados pela administração na busca de aperfeiçoamento e espaço competitivo.

Schumpeter (1982) e posteriormente os neoschumpeterianos esclareceram os temas e os fluxos capitalistas à luz de teorias, dentre elas a Evolucionária que, tomando por base os conceitos difundidos pelas ciências biológicas, demonstra como o meio reage a uma inovação. Consagrado como o "Pai da Inovação", Joseph Shumpeter dissertou sobre os ciclos de expansão e retração da economia capitalista. Segundo ele quem implementa novas combinações no sistema produtivo é inovador, não necessariamente inventor. As inovações devem ser praticadas para que surtam efeito na sociedade econômica. A esse "movimento" descrito por Schumpeter, as inovações mais antigas dão lugar as inovações recentes num processo que ele chama de "destruição criativa" (Ferreira, 2015; Ramos et al 2021).

Sob a ótica econômica evolucionária, a inovação é entendida como um processo que resulta de complexas interações em níveis local, nacional e mundial entre indivíduos, firmas e outras organizações voltadas à busca de capacitação tecnológica. (Figueiredo, 2004; Cunha et al, 2009)

Os estudiosos chamados de neoschumpeterianos reforçam as ideias de Schumpeter. Rosenberg (1982) tenta identificar vários tipos de aprendizagem e de que forma estes fazem parte de uma grande rede de atividades da inovação tecnológica. Para ele, o processo de aprendizagem pode provir de quatro formas: learning-by-doing ( $L B D)$, learning-by-using ( $L B U)$, learningby-searching (LBS) elou learning-by-interacting (LBI). Outra característica do pensamento de Rosenberg é que no meio econômico não é possível prever o que o mercado aceitará como um novo produto/processo. Assim o meio faz o processo de feedback constante as empresas. (Rosenberg, 1982; Júnior; Shikida; Dahmer, 2009).

Freeman (1987) definiu inovação em quatro categorias: a inovação incremental ocorre com maior ou menor intensidade continuamente em qualquer indústria ou atividade de serviço, sugerida por qualquer membro da entidade, ou fruto de uma nova política da organização; a inovação radical, aquelas que surgiram por outras empresas, universidades ou laboratórios; as mudanças do sistema tecnológico atingem as empresas de modo mais abrangente, podem afetar mais de um setor da economia; por fim a inovação do paradigma tecno-econômico, que ocorre a longo prazo, afeta quase toda a economia pois é um processo de junção de inovaç̃oes. (Santos; Fazion; Meroe, 2011).

Dosi, em seus estudos, busca entender o desenvolvimento tecnológico em uma analogia de ciência e tecnologia com a noção de paradigma científico de Thomas Kuhn. Para ele a inovação é a busca de resolução de problemas e elaboração de procedimentos para isso. "Na tentativa de explicar os determinantes, procedimentos e as direções da mudança técnica, assim como seus efeitos sobre o desempenho industrial e a mudança estrutural. (Dosi, 1984 e 1988).

Nesse sentido Nelson e Winter (1996) foram os construtores da teoria do desenvolvimento econômico, precursores da corrente neoschumpeteriana evolucionária, baseada na teoria da evolução das espécies. Estes autores destacam as rotinas da firma na inovação.

Como na teoria geral da evolução das espécies, "a visão neoschumpeteriana se estruturou, ao longo das duas últimas décadas, como tentativa sistemática de construir uma teoria geral da mudança em Economia". (Corazza; Fracalanza, 2004). Nelson e Winter usam para isso os conceitos de rotina, busca e seleção.

Para Maciel (2003) estes autores "visualizam as empresas no decorrer do tempo como possuindo rotinas que atuam para transformar os vários aspectos das suas características operacionais guiadas por regras que buscam novas rotinas no processo seletivo da concorrência capitalista". Portanto ela inova para se manter no mercado, de acordo com as regras pela teoria chamadas de "rotinas".

Os próprios Nelson e Winter $(1982,1990)$ descrevem sua teoria da seguinte forma:

Em nossa teoria evolutiva, estas rotinas fazem o papel que genes jogam em teoria evolutiva biológica. Elas são uma característica persistente do organismo e determinam seu possível comportamento (entretanto comportamento atual 
também é determinado pelo ambiente); eles são hereditários no sentido de que os organismos de amanhã gerados hoje (por exemplo, construindo uma planta nova) tenha muitas das mesmas características, e eles são selecionáveis no sentido que organismos com certas rotinas podem fazer melhor que outros, e, nesse caso, a sua importância relativa na população (indústria) é aumentada com o passar do tempo. (Nelson; Winter, 1982, p. 14 apud Maciel, 2003).

Para entender a forma como a perspectiva neoschumpeteriana aborda a questão da hereditariedade na economia, devese novamente fazer uma analogia entre os "genes" na biologia e as "rotinas". Nelson e Winter (1982) definem a rotina como a atividade repetitiva que está presente em uma organização. Desempenhar essas tarefas diariamente cria, conforme tratam os autores, um repertório de soluções aos problemas frequentes. Bem como o fato de serem realizadas com frequência lhe dá a característica de experimentação também fazem com que as tarefas sejam executadas mais rapidamente de melhor maneira. "A repetição e a experimentação estão na base da aprendizagem, por meio da qual são construídos os comportamentos". (Corazza; Fracalanza, 2004).

As rotinas criam uma condição de competitividade que pode ser acatada pelos agentes. Quando uma entidade percebe que não está acompanhando as rotinas, entra num processo de busca por uma nova. O mercado como um todo tem o papel de feedback no sentido de que adota ou exclui os processos ou produtos.

A Teoria Evolucionária fundamenta-se no o aprendizado, estando associada a um processo cumulativo onde as firmas ampliam seus conhecimentos, aperfeiçoam seus procedimentos e refinam suas habilidades em desenvolver, produzir e comercializar bens e serviços" (Nelson \& Winter, 1982; Dosi, 1988; Junior Rissardi; Shikida; Dahmer, 2009; Marins, 2009; Nelson \& Consoli, 2010; Silva Junior et al, 2021).

A firma é entendida como agente propulsor do desenvolvimento econômico e, neste sentido, a inovação tecnológica é crucial manter-se "viva" por meio de esforços intraorganizacionais, os quais estão diretamente relacionados às rotinas organizacionais e às competências da firma (Bell \& Pavitt, 1993; Nelson; Winter, 2005; Marins, 2009; Silva Junior et al, 2021).

Silva Júnior et al, (2021) assevera que as firmas que tiverem as suas rotinas mais adaptáveis às contingências do ambiente externo, serão as mais propensas ao crescimento e ao desenvolvimento. Dessa forma, a inovação surge a partir do momento que se necessita modificar as rotinas de atuação, em resposta aos novos paradigmas tecnológicos que emergem e às mudanças ambientais.

Esses mecanismos de aprendizagem e retroalimentação dos fluxos configuram-se como respostas às mudanças enfrentadas pelas organizações, em que o aprendizado contínuo, através das experiências organizacionais e a tradução dos conhecimentos na prática, contribuirá para desenvolver soluções inovadoras e, consequentemente, melhorar o desempenho e tornar as organizações mais competitivas (Cunha et al, 2009; Silva Junior, 2021; Nelson \& Consoli, 2010)

Especificamente, quanto à logística, tem-se as concepções de aprendizagem advindas da Teoria Evolucionária como uma alternativa para a análise e melhoria dos processos, por meio da coevolução.

Diante do exposto surge a seguinte questão problema: de que forma a Teoria Evolucionária pode contribuir para a melhoria dos processos logísticos? Voltando-se ao conhecimento do setor logístico de uma indústria de bens de consumo, elencando as não conformidades presentes em busca de soluções à luz da Teoria Evolucionária.

Sob a relevância teórica, a pesquisa justifica-se por levantar o arcabouço necessário para fundamentar a parte prática e apresentar reflexões sobre o estado da arte de temas como Teoria Evolucionária, logística, inovação e bom atendimento. Com enfoque no aprimoramento da logística interna, propiciando eventual embasamento para futuras pesquisas e aperfeiçoamento do tema no âmbito organizacional.

Entre os estudos que contemplam esses conceitos no meio acadêmico citam-se: Freeman (1974); Nelson \& Winter, (1982); Rosenberg (1982); Dosi, (1984 e 1988); Rissardi Júnior; Bell \& Pavitt, (1993); Figueiredo, (2004); Nelson; Winter, (1982 e 2005); Cunha et al, (2009); Shikida; Dahmer, (2009); Marins, (2009); Nelson \& Consoli, (2010); Silva Junior et al, 
(2021).

\section{Metodologia}

A metodologia empregada na elaboração deste trabalho coloca-se, quanto a sua objetividade, como descritiva. No que tange os procedimentos aplicados estarão presentes a pesquisa bibliográfica (pois busca amparo em diversos outros estudos que tangem a Teoria Evolucionária e a Logística), documental, estudo de caso (pois a base de dados provém de relatórios da empresa em estudo) e utiliza-se de abordagem ex-post-facto. Por tratar da solução de um conflito na empresa que se aplica, este estudo passa a ser classificado também como Pesquisa Ação. Além de compreender a pesquisa ação visa intervir na situação. O conhecimento que se busca é em torno da situação pesquisada.

No que confere a problemática da pesquisa, ela pode ser classificada como qualitativa. Tendo em vista que sugere uma visualização de problemática pela ótica teórica. O trabalho é qualitativo, pois não leva em conta a quantidade de dados coletados e informações, mas sim de uma maneira bastante particular visa analisar o setor logístico da empresa em estudo e propor melhorias com vistas a Teoria Evolucionária.

Os dados foram coletados do sistema de controle de inconformidades logísticas e de expedição, de uma empresa do ramo de bens de consumo, com fluxo elevado de cargas diárias para diversos lugares do país, pelo período de um ano. Os dados do período pesquisado foram organizados de três formas: todos os tipos de inconformidades que a empresa criou para classificar os erros; os tipos e seus volumes ocorridos no período analisado; e em uma classificação de relevância em relação ao desgaste com o cliente, para a proposta de melhoria.

\section{Resultados e Discussão}

\subsection{Processo logístico da empresa em estudo}

A pesquisa é realizada no setor logístico/processamento de pedidos de uma indústria de bens de consumo. Foi realizado um mapeamento do processo desde o recebimento de um pedido até a entrega da mercadoria, conforme organograma da Figura 1: 
Figura 1: Processo logístico da empresa

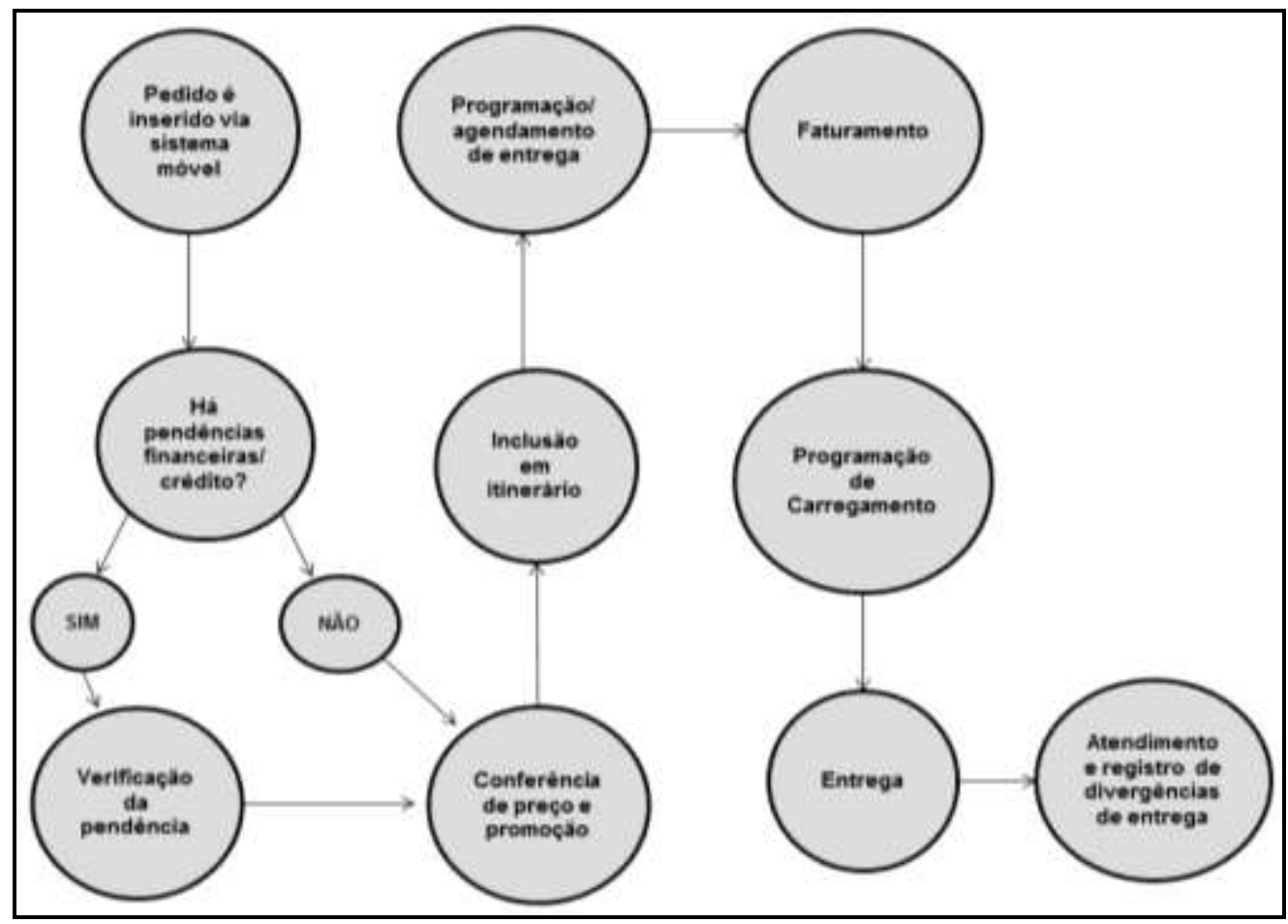

Fonte: Autores.

Os pedidos chegam via sistema digitado pelo representante. Se o cliente estiver com alguma pendência financeira, não tiver comprado nos últimos seis meses, ou fizer um pedido muito maior do que seus últimos, passa por uma análise. Essa análise visa verificar se houveram alterações de seus dados cadastrais, sua pontualidade, seu volume de compra em relação a sua capacidade de pagamento, entre outros. Só então o pedido terá preço e promoção analisados.

Se não houver problema financeiro o pedido passa diretamente ao setor comercial que analisa o preço e a proposta. Nesse momento são corrigidos os erros de preço, prazo, desconto, tamanho. Quando estiver correto o pedido é liberado para inclusão em itinerário logístico.

O setor de logística então inclui o pedido com demais pedidos da mesma região, ou se for um pedido suficiente para um transporte é ajustado ao tamanho do veículo. Nesse momento também são verificadas as informações logísticas que incluem, em que horário recebe, se o local da descarga suporta um caminhão grande, ou se o cliente necessita de agendamento para realização de descarga.

Depois de realizado o agendamento, as cargas são disponibilizadas as transportadoras, que negociam com o setor a entrega da mercadoria. Dada a transportadora, a carga segue para faturamento e passa a contar na lista de cargas a serem carregadas pelo setor de expedição.

\subsection{Inconformidades}

Em qualquer uma dessas fases pode ocorrer algum erro, que provavelmente repercutirá pouco após o carregamento ou no ato da entrega. O setor de ocorrências da empresa oferece o suporte para a solução de diferentes incongruências logísticas.

O registro é realizado por meio de sistema, onde o funcionário cadastra na referida nota fiscal o problema, e a solução mais acertada a ser tomada com a orientação dos demais setores e gerência, classificando-a de acordo com o fato. Existem 37 classificações de ocorrências no sistema, conforme Quadro 1: 
Quadro 1 - Tipos de inconformidades.

\begin{tabular}{|c|c|c|c|}
\hline \multicolumn{4}{|c|}{ Inconformidades } \\
\hline 1 & Alagamento & & Falta de mercadoria \\
\hline 2 & Atraso na entrega & 21 & Loja sem promotor \\
\hline 3 & Canhoto extraviado & 22 & Mercadoria danificada no ato da entrega \\
\hline 4 & Carregamento errado & 23 & Motorista não cumpriu o agendamento \\
\hline 5 & Cliente alegou que não fez pedido & 24 & Motorista não pagou a descarga \\
\hline 6 & Cliente está em balanço & 25 & Não coube mercadoria no caminhão \\
\hline 7 & Cliente não recebe por motivos internos & 26 & Não entra caminhão no local \\
\hline 8 & Cliente sem espaço físico & 27 & Pedido digitado em duplicidade \\
\hline 9 & Controle de qualidade do cliente & 28 & Pedido digitado errado \\
\hline 10 & Desacordo com o pedido & 29 & Problemas com o motorista \\
\hline 11 & Desconto não concedido ao cliente & 30 & Problema com a transportadora \\
\hline 12 & Divergência na leitura da NF-e & 31 & Produto sem cadastro \\
\hline 13 & Divergência no endereço do destinatário & 32 & Quebrou o caminhão \\
\hline 14 & Divergência no horário de recebimento & 33 & Reclamação de cliente \\
\hline 15 & Entrega no local errado & 34 & Sinistro de transporte \\
\hline 16 & Entrega para destinatário errado & 35 & Sobrou mercadoria no caminhão \\
\hline 17 & Erro no cálculo da substituição tributária & 36 & Substituição de NF-e \\
\hline 18 & Estabelecimento fechado & 37 & Valor da descarga \\
\hline 19 & Falha no agendamento & & \\
\hline
\end{tabular}

Fonte: Autores.

Observa-se, no Quadro 1, as inconformidades logísticas detectadas na empresa. Foram levantadas e categorizadas, totalizando 37 diferentes problemas que representam perdas financeiras para a empresa pois demandam de devoluções, deslocamentos desnecessários, ou simplesmente erros internos que facilmente poderiam ter sido evitados como, por exemplo, "pedido digitado errado" ou "não coube mercadoria no caminhão".

De acordo com as infomaçãoes repassadas pela empresa em estudo, foi realizada a tabulação das inconformidades no período de estudo. A Tabela 1 elenca as inconformidades ocorridas e as frequencias em que ocorreram.

Tabela 1: Inconformidades de janeiro a dezembro.

\begin{tabular}{l|c|l|c}
\hline \multicolumn{1}{c|}{ Tipo de inconformidade } & Volume & \multicolumn{1}{c|}{ Tipo de inconformidade } & Volume \\
\hline Alagamento & 3 & Falta de mercadoria & 202 \\
Atraso na entrega & 24 & Loja sem promotor & 3 \\
Canhoto extraviado & 440 & Mercadoria danificada no ato da entrega & 81 \\
Carregamento errado & 17 & Motorista não cumpriu agendamento & 6 \\
Cliente alegou que não fez pedido & 4 & Não coube mercadoria no caminhão & 7 \\
Cliente esta em balanço & 16 & Não entra caminhão no local & 24 \\
Cliente não recebe por motivos internos & 33 & Pedido digitado em duplicidade & 8 \\
Cliente sem espaço físico & 62 & Pedido digitado errado & 72 \\
Controle de qualidade do cliente & 64 & Problemas com Motorista & 17 \\
Desacordo com o pedido & 206 & Problemas com transportadora & 8 \\
Desconto não concedido ao cliente & 1 & Produto sem cadastro & 6 \\
Divergência na leitura da NF-e & 4 & Quebrou caminhão & 57 \\
Divergência no endereço do destinatário & 9 & Reclamação de Cliente & 9 \\
Divergência no horário de recebimento & 3 & Sinistro de Transporte & 6 \\
Entrega para destinatário errado & 9 & Sobrou mercadoria no caminhão & 2 \\
Erro no cálculo da substituição tributária & 21 & Substituição de Nota Fiscal & 6 \\
Estabelecimento fechado & 2 & Valor da descarga & 4 \\
Falha no agendamento & 100 & & \\
\hline \multicolumn{2}{c}{ TOTAL........................................................................ 1536 } & \\
\hline
\end{tabular}

Fonte: Autores. 
Verifica-se na Tabela 1, o rol de inconformidades detectadas na empresa, no setor de logística, bem como as respectivas frequencias. Destaque-se as ocorrências "canhoto extraviado" e "desacordo com o pedido" com as maiores frequências. No entanto, embora com menor representatividade, as inconformidades relativas a erros e/ou problemas com planejamento e execução são inadmissíveis e representam prejuízos e uma estrutura deficitária em controles dos seus fluxos.

O tipo de dado para a análise não foi filtrado com base no volume, pois o maior fluxo de ocorrências (canhoto extraviado) é um registro que diz respeito a controle de documentos de entregas de mercadorias pelas transportadoras responsáveis pela entrega. Ele ocorre no mesmo sistema. O volume é grande porque o registro da falta é realizado nota a nota. É uma situação que não afeta o relacionamento com clientes e não gera custos, apenas controla o pagamento realizado as empresas transportadoras no caso da não realização de uma entrega.

Com base no conteúdo presente em cada tipo de inconformidade, elas foram classificadas de 0 a 5 onde 0 significa não desgasta relacionamento/imagem da empresa para com o cliente e 5 pode desgastar relacionamento/imagem da empresa para com o cliente. A Tabela 2 elenca as inconformidades dentro do Score atribuído.

Tabela 2: Inconformidades logísticas classificadas em score.

\begin{tabular}{l|c|l|c}
\hline Inconformidades & Score & Inconformidades & Score \\
\hline Alagamento & 0 & Motorista não pagou a descarga & 4 \\
Canhoto extraviado & 0 & Não coube mercadoria no caminhão & 4 \\
Cliente está em balanço & 0 & Não entra caminhão no local & 4 \\
Divergência no endereço do destinatário & 0 & Sinistro de transporte & 4 \\
Estabelecimento fechado & 0 & Substituição de nfe & 4 \\
Problema com a transportadora & 0 & Atraso na entrega & 5 \\
Sobrou mercadoria no caminhão & 0 & Carregamento errado & 5 \\
Entrega no local errado & 1 & Cliente alegou que não fez pedido & 5 \\
Entrega para destinatário errado & 1 & Controle de qualidade do cliente & 5 \\
Problemas com o motorista & 1 & Desconto não concedido ao cliente & 5 \\
Valor da descarga & 2 & Falha no agendamento & 5 \\
Cliente não recebe por motivos internos & 2 & Falta de mercadoria & 5 \\
Cliente sem espaço físico & 2 & Mercadoria danificada no ato da entrega & 5 \\
Divergência na leitura da nf-e & 2 & Motorista não cumpriu o agendamento & 5 \\
Desacordo com o pedido & 3 & Pedido digitado em duplicidade & 5 \\
Divergência no horário de recebimento & 3 & Pedido digitado errado & 5 \\
Erro no cálculo da substituição tributária & 3 & Quebrou o caminhão & 5 \\
Loja sem promotor & 3 & Reclamação de cliente & 5 \\
Produto sem cadastro & 3 & & \\
\hline
\end{tabular}

Fonte: Autores.

Assim o estudo levou em conta as inconformidades classificadas com Score 5 de desgaste relacionamento/imagem da empresa para com o cliente. Os dados não foram filtrados novamente por volume, mas as que o setor de controle de inconformidades destaca como o mais frequente no fluxo geral de inconformidades.

O maior volume de inconsistências repousa nos relativos a data/horário de entrega, que, são geralmente registradas nos tipos 'Falha no agendamento', 'Atraso na entrega' e 'Motorista não cumpriu o agendamento'. Essas três inconformidades a serem analisadas estão destacadas na Tabela 4. Além disso, algumas situações desse mesmo conteúdo não são registradas no sistema, já que se solucionadas em contato com o cliente e com seu aval não geram custos extras não há necessidade de registro.

O tipo 'Falta de Mercadoria' é um tipo de inconformidade registrada no sistema a cada falta, por nota fiscal recebida de clientes. Apesar do grande volume e de não ser bom para o relacionamento com o cliente esse tipo de inconformidade pode não ser fruto da empresa, de seu controle logístico/expedição, mas do ato da descarga, com os demais envolvidos, como um erro na contagem de volumes, conforme demonstra a Tabela 3. 
Tabela 3: Inconformidades score 5 e frequências.

\begin{tabular}{l|c}
\hline \multicolumn{1}{c|}{ Inconformidades Score 5 } & Frequências \\
\hline Atraso na entrega & 24 \\
Carregamento errado & 17 \\
Cliente alegou que não fez pedido & 4 \\
Controle de qualidade do cliente & 64 \\
Desconto não concedido ao cliente & 1 \\
Falha no agendamento & 100 \\
Falta de mercadoria & 202 \\
Mercadoria danificada no ato da entrega & 81 \\
Motorista não cumpriu o agendamento & 6 \\
Pedido digitado em duplicidade & 8 \\
Pedido digitado errado & 72 \\
Quebrou o caminhão & 57 \\
Reclamação de cliente & 9 \\
\hline
\end{tabular}

Fonte: Autores.

A Tabela 3 apresenta as inconformidades classificadas como Score 5, objeto da análise deste estudo, e suas respectivas ocorrencias no período. Falta de mercadoria foi a inconformidade com maior frequência com 202 occorrências. Outras inconformidades como falha de agendamento, mercadoria danificada no ato de entrega e pedido digitado errado aparecem com frequências significativas e apontam para problemas no controle interno da empresa.

Assim sendo entra-se no mérito da origem dos três problemas destacados, de conteúdo semelhante. A falha no processo logístico pode ocorrer pelo espaço de tempo entre o carregamento da mercadoria e a data estipulada para a chegada desta ao destino. Esse espaço de tempo pode ser afetado por:

a) Falha na organização de prioridades da expedição;

b) Problemas com a comunicação entre o setor de expedição e a transportadora contratada para a entrega;

c) Problemas no trajeto (trânsito, bloqueios);

d) Problemas mecânicos no veículo;

Destes tópicos pode-se afirmar que os itens 'c' e 'd' não são passíveis de controle, já que a frota não é própria e problemas no trânsito como um todo podem ocorrer esporadicamente, independente de atitudes da empresa. O tópico 'b' elenca também um problema de caráter esporádico, pois geralmente o contato é via telefone.

O primeiro item, porém fazem parte do método adotado na expedição das mercadorias. A melhoria instaurada neste poderia expressar diminuição do volume de inconformidades do tipo 'Falha no agendamento', 'Atraso na entrega' e 'Motorista não cumpriu o agendamento’'

\subsection{Sistema logístico de expedição}

O sistema de expedição é o que controla os caminhões a serem carregados. O setor de expedição entra em contato com as transportadoras para organizar o carregamento dos caminhões. O critério de carregamento a ser observado é o da carga que possui agendamento no cliente de acordo com a região do país em que se encontra.

Tendo em vista a busca pela origem do problema, o sistema que controla a expedição foi analisado. O Quadro 2 é a representação em excel do sistema utilizado pela empresa para carregamento de veículos. Cada linha indica uma carga. O setor possui seis rampas físicas de carregamento, destacadas na imagem pelas primeiras linhas.

A primeira coluna denominada "Rampa" indica as saídas de mercadoria através dos veículos de carga. À medida que as cargas são carregadas elas saem da lista demonstrada pelo Quadro 2 e passam a constar em outro tipo de banco de dados. 
Quadro 2 -Reprodução do sistema de expedição de cargas da indústria

\begin{tabular}{|c|c|c|c|c|c|c|c|c|c|c|}
\hline Rampa & Início carreg. & Faturamento & Rota & Número & Nome & Motorista & Placa & Eixos & Quantidade & Peso \\
\hline \begin{tabular}{|r|}
1 \\
\end{tabular} & 01/01/2016 23:50 & $01 / 01 / 2016$ & mapa & 16 & Região sul agendada & Nome do motorista & Dígitos da & 3 & $x$ & $x$ \\
\hline 2 & 02/01/2016 00:50 & $01 / 01 / 2016$ & mapa & 27 & região centro-oeste & Nome do motorista & Dígitos da & 3 & $x$ & $x$ \\
\hline 3 & 02/01/2016 01:50 & $01 / 01 / 2016$ & mapa & 20 & Região Norte & Nome do motorista & Dígitos da & & $x$ & $x$ \\
\hline 4 & 01/01/2016 23:10 & $01 / 01 / 2016$ & mapa & 29 & Capital agendada & Nome do motorista & Dígitos da & 3 & $x$ & $x$ \\
\hline 5 & $01 / 01 / 201622: 55$ & $01 / 01 / 2016$ & mapa & 17 & Região sudeste 02/01 & Nome do motorista & Dígitos da & 3 & $x$ & $x$ \\
\hline 6 & 01/01/2016 23:32 & $01 / 01 / 2016$ & mapa & 26 & Região sul imediata & Nome do motorista & Dígitos da & & $x$ & $x$ \\
\hline- & & & mapa & 34 & Nome do cliente $04 / 01$ & Nome do motorista & Dígitos da & & $x$ & $x$ \\
\hline- & & $01 / 01 / 2016$ & mapa & 33 & Região nordeste agendada & Nome do motorista & Dígitos da & & $x$ & $x$ \\
\hline- & & & mapa & 32 & Região sul 03/01 & Nome do motorista & Dígitos da & & $x$ & $x$ \\
\hline- & & $01 / 01 / 2016$ & mapa & 31 & Nome do cliente $03 / 01$ & Nome do motorista & Dígitos da & & $x$ & $x$ \\
\hline- & & $01 / 01 / 2016$ & mapa & 30 & Nome do cliente $03 / 01$ & Nome do motorista & Dígitos da & & $x$ & $x$ \\
\hline- & & $01 / 01 / 2016$ & mapa & 28 & Nome do cliente $02 / ; 01$ & Nome do motorista & Dígitos da & & $x$ & $x$ \\
\hline- & & $01 / 01 / 2016$ & mapa & 19 & Região sudeste $02 / 01$ & Nome do motorista & Dígitos da & 5 & $x$ & $x$ \\
\hline- & & $01 / 01 / 2016$ & mapa & 18 & Região sudeste 02/01 & Nome do motorista & Dígitos da & & $x$ & $x$ \\
\hline
\end{tabular}

Fonte: Autores.

O Quadro 2 mostra, na segunda coluna data e horário de início de carregamento. A terceira coluna indica a data de emissão da nota da carga. Em seguida a coluna rota no sistema é um ícone que se aberto da a localização das entregas no mapa.

A coluna "Número" indica o código numérico dado pelo sistema a carga, em seguida o nome dado a carga, se já houver transporte a carga terá nome do motorista e número da placa bem como o numero de eixos que o veículo possui. Em seguida a coluna quantidade, que indica a quantidade em fardos constante na carga e por fim o peso da carga.

\subsection{Teoria evolucionária $x$ resolução das não conformidades}

As rotinas em teoria evolucionária representam as atividades repetitivas dentro de uma organização. Elas possibilitam a criação de um repertório de soluções aos problemas frequentes. A inconformidade referente a falha no agendamento exposta tem diversas origens e uma delas pode repousar no sistema em uso.

O sistema de expedição utilizado pela indústria mecaniza a organização das cargas que devem ser carregadas. Porém o controle de quais delas são prioridade, urgentes ou as que possuem o produto disponível em estoque não é realizado no sistema. Esse controle é paralelo ao sistema, deixando a informação retida no setor sem a possibilidade de visualização pelos demais antes da sua efetiva realização.

Uma forma de melhorar essa demanda, verificando a rotina e a frequente e simples situação de inconformidade é a inserção do controle de prioridades no sistema. O campo peso da carga daria lugar ao agendamento de carregamento. O quadro 3 faz analogia ao sistema utilizado pela empresa, mas com a inserção desse campo.

Com o novo layout a organização das cargas no sistema estaria em ordem de agendamento de carregamento realizado pelo setor. O setor de expedição então indicaria no sistema a hora agendada com a transportadora para o carregamento da mercadoria. No novo layout o campo peso da carga daria lugar a este de data de carregamento. 
Quadro 3: Reprodução do novo sistema de expedição.

\begin{tabular}{|c|c|c|c|c|c|c|c|c|c|c|}
\hline \multicolumn{11}{|c|}{ 02/01/2016 01:10H } \\
\hline Rampa & Início carreg. & Faturamento & Rota & Número & Nome & Motorista & Placa & Eixos & Quantidade & \begin{tabular}{|c|} 
Agendada para \\
carregamento
\end{tabular} \\
\hline 1 & 01/01/2016 23:50 & 01/01/2016 & mapa & 16 & Região sul agendada & Nome do motorista & Dígitos da Placa & & $\mathrm{x}$ & $1 / 1 / 1623: 00$ \\
\hline 2 & 02/01/2016 00:50 & $01 / 01 / 2016$ & mapa & 27 & Região centro-oeste & Nome do motorista & Dígitos da Placa & & $x$ & 1/1/16 23:30 \\
\hline 3 & 02/01/2016 01:50 & $01 / 01 / 2016$ & mapa & 20 & Região Norte & Nome do motorista & Dígitos da Placa & & $x$ & 1/1/16 23:30 \\
\hline 4 & 01/01/2016 23:10 & $01 / 01 / 2016$ & mapa & 29 & Capital agendada & Nome do motorista & Dígitos da Placa & & $x$ & 1/1/16 23:00 \\
\hline 5 & 01/01/2016 22:55 & $01 / 01 / 2016$ & mapa & 17 & Região sul 02/01 & Nome do motorista & Dígitos da Placa & & $x$ & 1/1/16 23:00 \\
\hline 6 & 01/01/2016 23:32 & 01/01/2016 & mapa & 26 & Região sul imediata & Nome do motorista & Dígitos da Placa & & $x$ & $1 / 1 / 1623: 00$ \\
\hline- & & $01 / 01 / 2016$ & mapa & 18 & Região sudeste $02 / 01$ & Nome do motorista & Dígitos da Placa & & $x$ & 1/1/16 23:00 \\
\hline- & & $01 / 01 / 2016$ & mapa & 28 & Nome do cliente $02 / 01$ & Nome do motorista & Dígitos da Placa & & $x$ & 2/1/16 3:00 \\
\hline- & & $01 / 01 / 2016$ & mapa & 19 & Região sudeste 02/01 & Nome do motorista & Dígitos da Placa & & $x$ & 2/1/16 3:00 \\
\hline- & & 01/01/2016 & mapa & 30 & Nome do cliente $03 / 01$ & Nome do motorista & Dígitos da Placa & & $x$ & 2/1/16 6:00 \\
\hline- & & $01 / 01 / 2016$ & mapa & 31 & Nome do cliente $03 / 01$ & Nome do motorista & Dígitos da Placa & & $x$ & $2 / 1 / 166: 00$ \\
\hline- & & & mapa & 32 & Região sul 03/01 & Nome do motorista & Dígitos da Placa & & $x$ & 2/1/16 8:00 \\
\hline- & & & mapa & 34 & Nome do cliente $04 / 01$ & Nome do motorista & Dígitos da Placa & & $x$ & 2/1/16 8:00 \\
\hline- & & $01 / 01 / 2016$ & mapa & 33 & Região nordeste agendada & Nome do motorista & Dígitos da Placa & 5 & $x$ & $2 / 1 / 168: 00$ \\
\hline
\end{tabular}

Fonte: Autores.

Com essa alteração, caso o cliente alterasse a data que gostaria de receber a mercadoria, o setor de agendamento já poderia visualizar se a data e hora de carregamento informadas seriam compatíveis com a nova data de entrega. Além disso, o setor de inconformidades poderia acompanhar possíveis incongruências entre os horários, podendo buscar uma solução antecipada.

Quanto aos tipos de inconformidades em que são classificados os fatos foi possível verificar que três tipos deles puderam ser suprimidos em um único, 'Falha no agendamento', 'Atraso na entrega' e 'Motorista não cumpriu o agendamento' em 'Falha no agendamento' pois seu conteúdo é semelhante e a origem do problema geralmente é a mesma.

No intuito de aprimorar os filtros de busca, uniformizar os tipos de inconformidades e eliminar tipos pouco utilizados mais tipos de inconformidades poder ser unificados: "Pedido digitado errado" e "Pedido digitado em duplicidade" em "Divergência de pedido"; "Controle de qualidade do cliente" e "Reclamação do cliente" em "Controle de qualidade do cliente"; "Divergência no endereço do destinatário", "Entrega no local errado" e "Entrega para destinatário errado" em "Divergência no local de entrega"; "Motorista não pagou a descarga" e "Valor de descarga" em "Valor de descarga"; "Problemas com o motorista" e "Problemas com a transportadora" em "Problemas com a transportadora". A planilha de tipos teria 08 tipos a menos, conforme Tabela 4:

Tabela 4: Relação de inconformidades logísticas atualizada

\begin{tabular}{c|l|c|l}
\hline Item & \multicolumn{1}{|c|}{ Inconformidades } & Item & \multicolumn{1}{|c}{ Inconformidades } \\
\hline 1 & Alagamento & 16 & Estabelecimento fechado \\
\hline 2 & Canhoto extraviado & 17 & Falha no agendamento \\
\hline 3 & Carregamento errado & 18 & Falta de mercadoria \\
\hline 4 & Cliente alegou que não fez pedido & 19 & Loja sem promotor \\
\hline 5 & Cliente está em balanço & 20 & Mercadoria danificada no ato da entrega \\
\hline 6 & Cliente não recebe por motivos internos & 21 & Não coube mercadoria no caminhão \\
\hline 7 & Cliente sem espaço físico & 22 & Não entra caminhão no local \\
\hline 8 & Controle de qualidade do cliente & 23 & Problema com a transportadora \\
\hline 9 & Desacordo com o pedido & 24 & Produto sem cadastro \\
\hline 10 & Desconto não concedido ao cliente & 25 & Quebrou o caminhão \\
\hline 11 & Divergência de pedido & 26 & Sinistro de transporte \\
\hline 12 & Divergência na leitura da NF-e & 27 & Sobrou mercadoria no caminhão \\
\hline 13 & Divergência no horário de recebimento & 28 & Substituição de nota fiscal \\
\hline 14 & Divergência no local de entrega & 29 & Valor da descarga \\
\hline 15 & Erro no calculo da substituição tributária & & \\
\hline
\end{tabular}

Fonte: Autores.

A Tabela 4 mostra a relação de não conformidades atualizadas, após as soluções apresentadas. Os conceitos de 
rotinas, busca e seleção aplicados ao setor indicam que a rotina do fluxo representativo das inconformidades de agendamento/entrega, instigou a busca pelas origens do problema, a seleção de informações relevantes não presentes, e descarte de uma que pode ser suprimida nesse meio.

\section{Considerações Finais}

Os conceitos de rotina, aprendizado e inovação apresentados pelos autores neoschumpeterianos, bem como os processos que envolvem a criação e o aprendizado foram inseridos no meio micro.

A teoria evolucionária remete a inovação através do aprendizado. No sentido macro os estudiosos destacam a necessidade de se inovar para manter-se ativo no meio econômico. No sentido micro inovar faz-se necessário para melhorar os processos e diminuir inconsistências.

Nesse estudo foram detectadas inconformidades do sistema logístico de uma empresa e destas rastreadas as mais relevantes e suas possíveis causas. Por meio da rotina foi possível buscar uma solução aplicável com vistas a possível diminuição do problema.

Com o objetivo de verificar de que forma a Teoria Evolucionária pode contribuir para a melhoria dos processos logísticos, a pesquisa apresentou o levantamento das não conformidades logísticas da empresa estudada e, usando os conceitos teóricos preconizados pelos autores neoschumpeterianos, propôs soluções.

A teoria evolucionária é aplicável ao setor interno de uma empresa, pois instiga o aprendizado, inovação e busca pela melhoria. Eliminando, portanto, as rotinas inconsistentes e desnecessárias e implementando novas.

Os resultados encontrados apontam para relevância das rotinas no aprendizado que, uma vez aprimoradas, refletem-se em soluções para os problemas, em virtude da especialização e aprendizado advindos com a otimização dos processos.

Dessa forma busca-se a otimização de recursos, com a melhoria dos processos eliminando as inconformidades e consequentemente reduzindo custos. A Teoria Evolucionária contribui na análise e investigação dos processos logísticos, nesse caso; identificação dos pontos inconformes, que com o aprendizado dos processos e métodos de forma constante.

Sugere-se que novas pesquisas sejam realizadas na empresa visando acompanhar a diminuição das inconformidades e/ou identificação de novas formas de incongruências. Ademais, é salutar contínuo planejamento e medição de desempenho dos processos, melhor comunicação entre os setores da empresa e implementação de práticas colaborativas que visem a interação e melhoria dos fluxos internos.

\section{Referências}

Bell, M., \& Pavitt, K. (1993). Technological accumulation and industrial growth: contrasts between developed and developing countries. Industrial and corporate change, 2(2), 157-210. https://doi.org/10.1093/icc/2.2.157

Corazza, R.I; Fracalanza, P.S. (2004). Caminhos do pensamento neo-schumpeteriano: para além das analogias biológicas. Revista Nova Economia. Belo Horizonte.

Cunha, S. K., Bulgacov, Y. L., Meza, M. L. F., \& Balbinot, Z.. (2009). O sistema nacional de inovação e a ação empreendedora no Brasil. Revista Base (Administração e Contabilidade) da Unisinos, 6(2), 120-137

Dosi, G. (1988). The nature of the innovative process. In: Dosi, G., Freeman, C., Nelson, R., Silverberg, G. \& Soete, L. (eds.). Technical change and economic theory. Londres: Pinter Publishers

Dosi, G. (1984) Technical change and industrial transformation. New York: St. Martin’s Press

Ferreira, D. (2015) Schumpeter e a Inovação. Consultoria econômica. 〈http://peritiaeconomica.com.br/schumpeter-inovacao/>.

Figueiredo, P.N. (2004) Aprendizagem tecnológica e inovação industrial em economias emergentes: uma breve contribuição para o desenho e implementação de estudos empíricos e estratégias no Brasil. Revista Brasileira de Inovação, 3(2):323-361.

Freeman, C. (1974). Innovation and the strategy of the firm. In: Freeman, C. The economics of industrial innovation. Harmondsworth: Penguin Books

Freeman, C.; Clark, J.; Soete, L. (1982) Unemployment and technical innovation. London: Frances Pinter 
Research, Society and Development, v. 10, n. 16, e371101623688, 2021

(CC BY 4.0) | ISSN 2525-3409 | DOI: http://dx.doi.org/10.33448/rsd-v10i16.23688

Freeman, C. (2004). System of innovation in historical perspective. Revista Brasileira de Inovação, 9-34

Júnior, D. J.R; Shikida, P. F.A; Dahmer, V.S. (2009). Inovação, tecnologia e concorrência: uma revisita ao pensamento neoschumpeteriano. Economia \& Tecnologia. Ano 05, Vol. 16. UFPR

Mohammad, H.I. (2019) Mediating effect of organizational learning and moderating role of environmental dynamism on the relationship between strategic change and firm performance. Journal of Strategy and Management, 12(2), 275-297 DOI: https://doi.org/10.1108/JSMA-07-2018-0064

Maciel, R. C. G. (2003). Ilhas de alta produtividade: inovação essencial para a manutenção dos seringueiros nas reservas extrativistas. 2003. 88 f. Dissertação (Mestrado em Desenvolvimento Econômico, Espaço e Meio Ambiente) - IE, UNICAMP, Campinas

Marins, L.M. (2009) Economia, tecnologia e inovação: da teoria da firma à gestão da inovação. Revista Eletrônica de Ciência Administrativa, [S.1.], v. 6, n. 1, p. 1-14, jun. DOI: https://doi.org/10.21529/RECADM.20070601003

Nelson, R. \& Winter, S. (1982) An evolutionary theory of economic change. Cambridge: Harvard University.

Nelson, R.; Consoli, D. (2010) An evolutionary theory of household consumption behavior. Journal of Evolutionary Economics, v. 20 , n. 5, p. 665-687. https://doi.org/10.1007/s00191-010-0171-7

Rosenberg, N. (1982) Inside the black box: technology and economics. Cambridge: Cambridge University Press

Ramos, M. P. da S.., Stroparo, T. R.., \& Cordeiro, G. (2021). Inovações tecnológicas em empresas madeireiras do município de Imbituva/PR: uma análise sob à égide da teoria evolucionária. Revista Ibero-Americana De Humanidades, Ciências E Educação, 7(11), 859-878. https://doi.org/10.51891/rease.v7i11.3119

Santos, A.B.A.; Fazion, C. B.; De Meroe, G. P. S.; (2011) Inovação: um estudo sobre a evolução do conceito de Schumpeter. Revista Pontifícia Universidade de São Paulo.

Shikida, P., \& Bacha, C. (1988) Notas sobre o modelo schumpeteriano e suas principais correntes de pensamento. Revista Teoria E Evidência Econômica, 5(10). DOI: https://doi.org/10.5335/rtee.v5i10.4779

Schumpeter, J.A. (1982) Teoria do desenvolvimento econômico: uma investigação sobre lucros, capital, crédito juro e o ciclo econômico. São Paulo, Abril, 169 p. 1982.

Silva Junior, A. C., \& Emmendoerfer, M. L. (2021). Novas Formas Organizacionais no Setor Público: os Laboratórios de Inovação de Governo sob a Ótica da Teoria Neoschumpeteriana. Navus: Revista de Gestão e Tecnologia, 11(1), 65-78. DOI: https://doi.org/10.22279/navus.2021.v11.p01-13.1470

Yuliansyah, Y., \& Jermias, J. (2018). Strategic performance measurement system, organizational learning and service strategic alignment: Impact on performance. International Journal of Ethics and Systems. 34(4), 564-592. DOI: https://doi.org/10.1108/IJOES-07-2018-0102 